\title{
Behavioural and demographic predictors of adherence to three consecutive faecal occult blood test screening opportunities: a population study
}

Amy Duncan ${ }^{1 *}$, Deborah Turnbull ${ }^{1}$, Carlene Wilson ${ }^{2,3}$, Joanne M Osborne ${ }^{3,4}$, Stephen R Cole C, $^{3,4}$, Ingrid Flight ${ }^{5}$ and Graeme P Young 3,4

\begin{abstract}
Background: Social cognitive variables are often examined for their association with initial participation in colorectal cancer screening. Few studies have examined the association of these variables with adherence to multiple screening offers i.e., rescreening. This study aimed to describe patterns of participatory behaviour after three rounds of screening using faecal immunochemical tests (FIT) and to determine social cognitive, demographic and background variables predictive of variations in adherence.

Methods: Participants were 1,540 men and women aged 50 to 75 living in South Australia who completed a behavioural survey measuring demographic (for example, age, gender) and social cognitive variables relevant to FIT screening (for example, perceived barriers, benefits, self-efficacy). The survey was followed by three, free FIT screening offers mailed on an annual basis from 2008 to 2010. Patterns of participation after three screening rounds were described as one of five screening behaviours; 1) consistent re-participation (adherent with all screening rounds), 2) consistent refusal (adherent with no screening rounds), 3) drop out (adherent with earlier but not later rounds), 4) intermittent re-participation (adherent with alternate rounds) and 5) delayed entry (adherent with later but not initial round(s)). Univariate (Chi Square and Analysis of Variance) and multivariate (Generalised Estimating Equations) analyses were conducted to determine variables predictive of each category of non-adherence (those that did not participate in every screening offer, groups 2, 3, 4 and 5) relative to consistent re-participation.

Results: Significant social cognitive predictors of non-adherence were; less self-efficacy (drop out and consistent refusal), greater perceived barriers (drop out) and lower levels of response efficacy (consistent refusal). Demographic predictors of non-adherence included; male gender (delayed entry), younger age (intermittent, delayed and consistent refusal), less frequent GP visits (intermittent re-participation) and 'ancillary only' private health insurance (drop out). Less satisfaction with screening at baseline predicted drop out, consistent refusal and delayed entry.

Conclusions: Different combinations of demographic and behavioural variables predicted different patterns of rescreening adherence. Rescreening interventions may benefit from a targeted approach that considers the different needs of the population subgroups. Satisfaction with past FOBT screening measured prior to the study screening offers was an important predictor of adherence.
\end{abstract}

Keywords: Colorectal cancer, Faecal occult blood test, Rescreening, Adherence, Psychological factors

\footnotetext{
* Correspondence: amy.duncan@adelaide.edu.au

'School of Psychology, The University of Adelaide, Adelaide 5005, South

Australia, Australia

Full list of author information is available at the end of the article
}

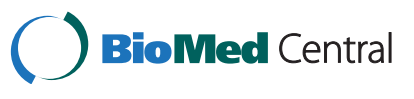

(c) 2014 Duncan et al.; licensee BioMed Central Ltd. This is an Open Access article distributed under the terms of the Creative Commons Attribution License (http://creativecommons.org/licenses/by/2.0), which permits unrestricted use, distribution, and reproduction in any medium, provided the original work is properly credited. The Creative Commons Public Domain Dedication waiver (http://creativecommons.org/publicdomain/zero/1.0/) applies to the data made available in this article, unless otherwise stated. 


\section{Background}

Adherence to recommendations for screening with faecal occult blood tests (FOBT) has been shown to reduce incidence of, and mortality from, colorectal cancer (CRC) [1]. In Australia, screening using faecal immunochemical tests for haemoglobin (FIT, a type of FOBT) is recommended at least once every two years for those aged 50 and over $[2,3]$. Screening programs utilising FOB-based tests have been established in many countries including The Netherlands, Italy, the United Kingdom, Australia and France [4,5]. Initial uptake and continued adherence to screening recommendations are crucial to the success of these programs $[3,6]$. Recent research has highlighted the importance of using longitudinal observations of screening participation to measure adherence adequately [7-11]. Studies of this nature have documented low rates of ongoing adherence ranging from $13.7 \%$ [7] to $39.2 \%$ [11] for recommended levels of screening participation (i.e., participation in all screening offers) over more than two screening rounds. These findings highlight the importance of moving beyond identification of the factors that predict initial uptake to those associated with screening relapse (i.e., program dropout) and other irregular patterns of participation.

The majority of past CRC screening research has focused on predictors of participation in single screening opportunities (i.e., initial uptake or other one-off opportunities) [12-14]. These studies have established the utility of including social cognitive measures to explain initial screening participation and form the basis of many behavioural interventions to improve adherence [12-14]. Our previous work has extended this in order to explore the relationship between social cognitive variables and intention to rescreen. Significant predictors of rescreening intention included satisfaction with prior FOBT screening, awareness of the need to repeat screening, greater self-efficacy, greater perceived benefits of screening and fewer perceived barriers [15]. The focus of the current study was to determine predictors of consecutive participation in more than one screening opportunity (i.e., repeat or continued adherence) which, from here on, will be referred to as rescreening. Existing research on rescreening has, to date, been primarily limited to an examination of demographic and background (i.e., health systems) factors [9,10,16-19]. Significant positive predictors include greater frequency of general practitioner (GP) visits $[17,19]$, older age $[17,18]$ and male gender $[9,17]$. However, no studies have examined the utility of social cognitive variables for predicting ongoing adherence.

Recent research has highlighted the importance of utilising descriptive frameworks that encompass multiple participatory patterns of behaviour when measuring, and predicting, rescreening adherence $[9,11,18,20]$. These frameworks not only allow for the exploration of variables predictive of different non-adherent behaviours (for example, drop out behaviour, consistent non-participation) $[9,11,18,20]$ but they also provide a more accurate measure of ongoing adherence compared to cross sectional data [7]. There is evidence to suggest that interventions targeted to population subgroups are more successful in encouraging participation than a standard population approach $[21,22]$. Identifying the needs of different non-adherent subgroups could therefore inform the development of interventions to target demographic or behavioural factors that predict various patterns of non-adherent behaviour [9].

The primary aim of this study was to identify factors significantly associated with different categories of adherence defined according to patterns of participation observed after three annual FIT screening offers. Potential social cognitive, demographic and background factors measured at baseline, prior to the first screening offer, and derived from behavioural models that have successfully predicted initial screening uptake [12] were tested for their ability to predict variations in rescreening adherence. The study also aimed to explore the additional contribution of satisfaction with screening, measured prior to the study screening offers, on adherence to patterns of rescreening in the study.

\section{Methods}

\section{Study population}

The study population were 4000 men and women aged 50-75, residing in the surrounding suburbs of Adelaide, South Australia, who were selected at random from data provided by the Australian electoral roll. Elector details were cross checked against a CRC high risk database at the Bowel Health Service (BHS) Repatriation General Hospital in South Australia. Those known to be at high risk for CRC (as identified in the database), defined as having a personal or family history of CRC, or long standing irritable bowel conditions [23], were excluded from possible selection.

\section{Study design}

This study consisted of two phases; the survey phase (baseline) and the screening phase (following baseline). All social cognitive, demographic and background variables utilised in this study were measured in the baseline behavioural survey and used to predict participation in three subsequent screening offers (prospective design).

Participants were mailed a baseline behavioural survey in November of 2008 (survey phase). Those who completed the survey were then invited to participate in free FIT screening coordinated by the BHS on an annual basis for a period of three years (screening phase). In the first instance, survey respondents were mailed the FIT two weeks following return of the survey. Subsequent screening offers were mailed from October 2009 and 
September 2010, approximately one and two years after the initial offer. Offers were not mailed when 1) an invitee contacted the BHS to opt out of the study or 2) a positive test result in a preceding round, with follow up diagnostic evaluation, precluded the need for further offers. Participants provided informed consent to participate in the study via return of the completed survey and for each screening offer via return of a participant details and consent form and/or return of the completed FIT.

\section{Materials}

\section{Behavioural survey}

The survey, administered before the first screening offer (baseline), was designed to collect information on a variety of social cognitive, demographic and other background variables likely to predict rescreening. This survey has also been described in detail in a paper that reports associations with rescreening intention [15].

Demographic variables Demographic variables included age, gender, education, employment, level of private health insurance coverage and index of relative socioeconomic disadvantage defined according to postcode [24].

Social cognitive variables Social cognitive measures were; barriers and benefits of FOBT screening, perceived CRC susceptibility and severity, level of social influence (from family, friends and health professionals) to screen, a general measure of perceived social support, selfefficacy for completing screening, confidence in FOBT effectiveness (response efficacy), chance health locus of control (belief that health is controlled by chance), internal health locus of control and health value. Social cognitive items (excluding response efficacy which utilised a three point scale with response options of no, unsure and yes) were measured using 5 point Likert scales ranging from strongly disagree to strongly agree. Existing scales were used where possible and example items are provided in Table 1. The measures of perceived barriers and benefits included items from a previous questionnaire designed to measure beliefs regarding initial screening uptake [25] along with new items designed to assess barriers and benefits of rescreening (for example, "having regular home stool tests would give me peace of mind about my health"). A new measure of self-efficacy was also developed for this questionnaire based on the measurement recommendations of Luszczynska and Schwarzer [26].

Background variables Participants' knowledge of CRC risk factors (age, family history and lifestyle/diet) and CRC screening (the importance of early detection and treatment, the need to rescreen) were measured using 6 items (example; 'it is not necessary to screen again for bowel cancer if your previous screening test was normal') with response options yes, no and don't know/unsure. Three yes/no items measured participants' social interactions concerning CRC (known anyone who has had bowel cancer) and screening (discussed home stool testing with anyone, known anyone who has used a home stool test). Other background items included; frequency of general practitioner visits in the year preceding the study (ranging from none to five or more visits) and engagement in other types of cancer screening behaviour (yes or no). Family history of CRC and prior cancer diagnoses (other than CRC) were also measured.

Participants were asked if they had used an FOBT to screen for bowel cancer prior to their involvement in the present study (self-report past FOBT use). Those who

Table 1 Social cognitive items included in the behavioural questionnaire

\begin{tabular}{|c|c|c|c|}
\hline Variable & Example & Items & Source \\
\hline $\begin{array}{l}\text { Chance health locus } \\
\text { of control }\end{array}$ & "My good health is largely a matter of good fortune" & 4 & Wallston et al. [27] \\
\hline $\begin{array}{l}\text { Internal health locus } \\
\text { of control }\end{array}$ & "If I take the right actions I can stay healthy" & 2 & Wallston et al. [27] \\
\hline Health value & "If you don't have your health you don't have anything" & 4 & $\begin{array}{l}\text { Lau \& Hartman } \\
\text { [28] }\end{array}$ \\
\hline Response efficacy & "Participation in home stool test screening leads to early detection if something is wrong." & 4 & Boer \& Seydel [29] \\
\hline Self-efficacy & $\begin{array}{l}\text { "I am confident that I will be able to screen regularly for bowel cancer with a home stool test } \\
\text { even if I find the test to be embarrassing" }\end{array}$ & 6 & - \\
\hline Barriers & "Home stool tests are inconvenient" & 7 & - \\
\hline Benefits & "Screening can pick up bowel cancer early when it can be easily treated" & 4 & - \\
\hline Severity & "The health consequences of developing bowel cancer are severe" & 2 & Gregory et al. [25] \\
\hline Susceptibility & "Compared to other people my age my chance of getting bowel cancer is high" & 2 & Gregory et al. [25] \\
\hline Social support & "I can count on my friends when things go wrong" & 6 & Gregory et al. [25] \\
\hline Social influence & "My doctor thinks I should have bowel cancer screening" & 4 & Tiro et al. [30] \\
\hline
\end{tabular}


indicated that they had previously used a FOBT were asked to indicate their overall satisfaction with their past screening experience on a 5 point Likert scale ranging from very unsatisfied to very satisfied.

\section{FIT screening offer}

Annual screening offers were mailed from the BHS and included; 1) an invitation letter, 2) a two sample immunochemical FIT kit (OC-Sensor, Eiken Chemical Co., Tokyo, Japan), 3) a bowel cancer information brochure, 4) a combined participant details and consent form, 5) a reply-paid envelope and 6) a screening status information form where participants could provide details of participation in other CRC screening tests outside of the study. Reminder letters were mailed to non-participants after six weeks.

\section{Study outcomes}

Screening adherence, determined after three annual FIT screening rounds, was the primary outcome of the study. Adherence per round was measured based on either return of the completed study FIT or self-reported adherence with other CRC screening (for example, colonoscopy or FOBT obtained elsewhere) within the yearly observation period for each offer. Self-report was obtained either via the screening status information form or by participants contacting the BHS directly. Those reporting use of endoscopic screening, (colonoscopy or flexible sigmoidoscopy), with or without study FIT utilisation, were excluded from analyses. This exclusion was because the focus of this study was to determine the relevance of questionnaire variables to the prediction of rescreening adherence using FOB-based screening tests.

Participants were coded as adherent (Y) or nonadherent $(\mathrm{N})$ for each round resulting in eight possible patterns of participation. Participants were first coded according to participation in the study FIT. Additional self-report data for participation in other FOBTs were then included. This process ensured that observed FIT participation was the main source of data, which was then supplemented with self-report data.

\section{Defining patterns of participatory behaviour}

The eight possible patterns of participation were collapsed into five categories of adherence behaviour based on those described by Cole et al. [9]. The categories were; consistent re-participation (adherent with all screening rounds; target behaviour), consistent refusal (adherent with no screening rounds), drop out (participation round one and/or round two followed by subsequent refusal) and delayed entry (initial refusal followed by participation in later rounds). An additional behavioural category, intermittent re-participation, was also included in order to describe those who dropped out in round two but then re-participated in the final screening round. The eight participation patterns and associated adherence categories are described in Table 2.

\section{Analyses}

Primary analyses Univariate (ANOVA and Chi squared) comparisons with post hoc tests (Hochberg GT2 and Chi Square with a Bonferroni correction) were conducted comparing consistent re-participation with each remaining category (the 'non-adherent' categories; drop out, intermittent re-participation, delayed entry, consistent refusal) for each of the demographic, background and social cognitive variables. Skewed variables were analysed using nonparametric alternatives [31]. Significant differences determined at the univariate level were then incorporated into four separate multivariate models, utilising log Poisson Generalised Estimating Equations (GEE), with consistent re-participation as the referent category.

Secondary analyses To determine the impact of satisfaction with screening before study involvement on adherence to screening offered during the study, a second multivariate analysis was conducted on the subpopulation of participants who indicated in the baseline survey that they had used an FOBT in the past (self-reported past FOBT use). These models incorporated all the variables included in the primary multivariate analyses with the addition of a single item measure of satisfaction with past screening.

\section{Exclusions}

Questionnaire response rate was 48.5\% (1941/4000). Thirteen respondents requested no further contact following questionnaire completion therefore annual screening was offered to the remaining 1928 respondents. Screening invitees who participated in endoscopic screening (colonoscopy/FS; $\mathrm{n}=240,12.4 \%$ ) and those with incomplete questionnaire data $(n=148,7.6 \%)$ were excluded from analyses. The remaining 1,540 questionnaire respondents $(79.3 \%)$ were included in the analyses for this study as outlined in Figure 1.

\section{Ethical considerations}

This study has been approved by the Human Research Ethics Committees at the University of Adelaide and the Repatriation General Hospital.

\section{Results}

\section{Description of the sample}

The final sample $(n=1540)$ comprised $710(46.1 \%)$ men and 830 (53.9\%) women aged 50-75 (mean $=59.94, \mathrm{SD}=$ 6.48). Of the study sample $1,412(91.75 \%)$ participated only in the FIT offered by the BHS whilst the remaining 128 (8.25\%) reported other FOBT participation either in 
Table 2 FIT screening patterns and behaviours defined after three annual screening rounds

\begin{tabular}{cccc}
\hline Round $\mathbf{1}$ & $\begin{array}{c}\text { Participation patterns across three screening rounds } \\
\text { Round 2 }\end{array}$ & Round 3 & Adherence category \\
\hline$Y$ & $Y$ & $Y$ & Consistent re-participation \\
\hline$Y$ & $Y$ & $N$ & Drop out \\
$Y$ & $N$ & $N$ & Intermittent re-participation \\
$N$ & $Y$ & $Y$ & Delayed entry \\
\hline$Y$ & $N$ & $Y$ & $Y$ \\
\hline$N$ & $Y$ & $N$ & Consistent refusal \\
\hline$N$ & $N$ & $N$ & $N$
\end{tabular}

addition to, or instead of, the screening offered by the BHS. The majority were married ( $\mathrm{n}=1189,77.2 \%)$, had completed at least secondary school education $(\mathrm{n}=1041$, 67.6\%), spoke English at home $(\mathrm{n}=1329,86.3 \%)$, were born in Australia ( $\mathrm{n}=1094,71.0 \%)$, and just over half were still in the workforce $(n=802,52.1 \%)$. Index of relative disadvantage scores were divided into quintiles with the lowest quintile (1) indicating greater levels of disadvantage and the highest (5) indicating lower levels of disadvantage. A substantial portion of participants were in the highest $(\mathrm{n}=453,29.4 \%)$ and lowest quintiles ( $\mathrm{n}=326$, $21.2 \%$ ) with the remainder spread approximately evenly between. These scores indicate that participants were from a broad range of socioeconomic backgrounds with slightly larger clusters at each extreme. Compared to survey non respondents, survey respondents were more likely to be from less disadvantaged areas $\left(\chi^{2}(4)=68.36, \mathrm{p}<.001\right)$ and were slightly less likely to be from the youngest (50-54,
$55-59)$ and oldest $(70-74)$ age groups $\left(\chi^{2} \quad(5)=24.92\right.$, $\mathrm{p}<.001)$.

\section{Rescreening adherence}

Table 3 shows the proportion of participants for each category of adherence. Just over $55 \%$ of invitees were adherent with annual screening after three years.

\section{Univariate differences between consistent re-participation and non-adherence}

Table 4 shows the significant univariate predictors of categories of non-adherence compared to consistent reparticipation. Significant post hoc comparisons, indicated with asterisks, highlight differences between consistent re-participation and each of the non-adherent categories. Social cognitive variables only differentiated consistent re-participation from drop out and consistent

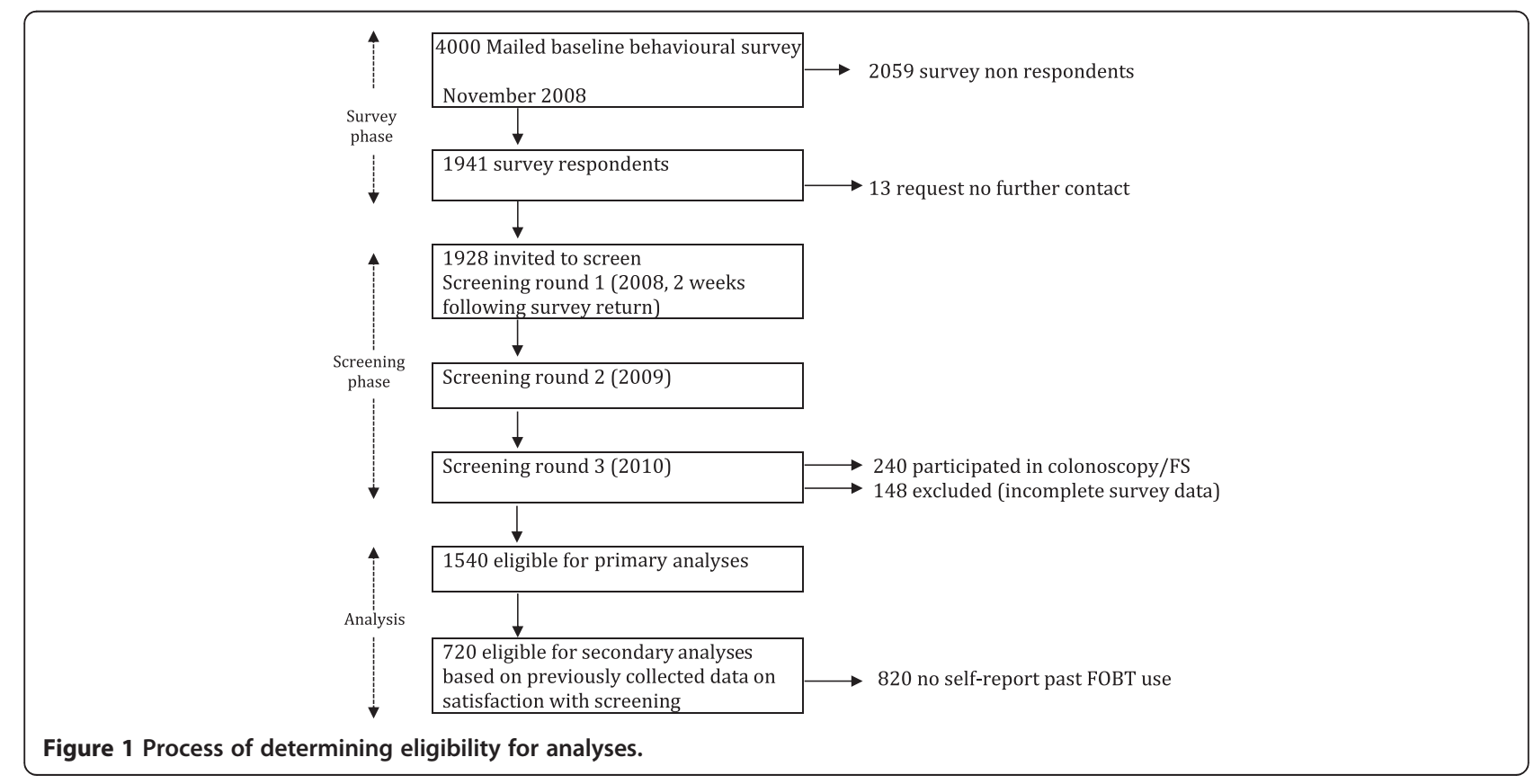


Table 3 Proportion of study participants in each adherence category upon study completion (i.e., at year 3)

\begin{tabular}{ll}
\hline Adherence category & Number (\%) \\
\hline Consistent re-participation & $860(55.8 \%)$ \\
Drop out & $134(8.7 \%)$ \\
Intermittent re-participation & $68(4.4 \%)$ \\
Delayed entry & $166(10.8 \%)$ \\
Consistent refusal & $312(20.3 \%)$ \\
Total & $1540(100 \%)$ \\
\hline
\end{tabular}

refusal. Demographic predictors were identified for all behavioural categories as shown in Table 5 .

\section{Multivariate predictors of non-adherence (primary analyses)}

Table 6 presents the results of four separate multivariate models with consistent re-participation as the referent category for each. Risk ratios (RR) above 1 indicate an increase in the likelihood of being in the comparative non-adherent category compared with consistent reparticipation, and a value below 1 indicates a decrease in likelihood. All social cognitive variables were measured on an increasing scale. Only variables that were identified post hoc as being associated with each category were entered into the multivariate models, therefore each model varies in terms of potential predictors. Significant multivariate predictors are highlighted in bold.

Three social cognitive variables significantly predicted variations in adherence; a perception of more extensive barriers and lower confidence in utilising the FIT (i.e., less selfefficacy) predicted drop out behaviour. Lower confidence in both personal capacity (i.e., self-efficacy) and test effectiveness (i.e., response efficacy) significantly predicted consistent refusal although the risk ratios were small.

Several demographic and background variables predicted non-adherence to rescreening. Significant predictors of drop out were; having 'ancillary' only private health insurance cover and no past FOBT use ${ }^{\mathrm{a}}$. Younger age and fewer GP visits in the year preceding the study predicted intermittent re-participation, whilst those who entered the screening program later (delayed entry) were more likely to be male and younger, and less likely to have known someone who has screened with a FOBT. Those who consistently refused the screening offers were less likely to be from areas of moderate disadvantage, were younger, had not used a FOBT in the past and were less likely to have known someone else who had used a FOBT.

\section{Satisfaction with past FOBT use (secondary analyses)}

A measure of satisfaction was only available for participants who reported in the baseline questionnaire that they had participated in FOBT screening before being invited into the present study (self-reported past FOBT use, $n=720$ ). Among this subsample there were substantially more participants in the consistent re-participation category $(\mathrm{n}=482,66.9 \%)$ and substantially less in the consistent refusal category ( $\mathrm{n}=78,10.8 \%$ ) when compared to the full sample. Proportions of those in the delayed entry $(n=83,11.5 \%)$, intermittent re-participation $(\mathrm{n}=32,4.4 \%)$, and drop out $(\mathrm{n}=45,6.3 \%)$ categories remained relatively similar in the subpopulation.

Details of past screening were limited to a single item measure of overall satisfaction with the screening experience. To determine the potential impact of satisfaction with past screening on non-adherence to the screening offered in this study the multivariate models described previously (primary analyses) were repeated for the reduced sample with the addition of the satisfaction measure as shown in Table 7. Contrary to the primary analyses, social cognitive variables did not differentiate categories of non-adherence amongst a sample of participants who had previously participated in FOBT screening when satisfaction with past screening was taken into account. However, less satisfaction with past screening, was significantly predictive of all non-adherent behaviours with the exception of intermittent re-participation.

\section{Discussion}

Recent studies have highlighted the importance of monitoring longitudinal screening adherence in order to measure rescreening accurately $[7,9,11]$. In this study, ongoing adherence was measured according to a predefined framework that described a variety of screening behaviour patterns over a period of three years [9]. Results show just over $55 \%$ of participants provided with annual invitations to screen with FIT were adherent with all three rounds. A substantial portion of participants were non-responsive to all invitations (20.3\%), and irregular patterns of adherence were observed for the remaining $24 \%$.

The substantial portion of those who participated at irregular intervals, or refused screening altogether, over a three year time frame highlight the importance of identifying ways to encourage ongoing adherence in order to maximise the population benefit of FOB-based screening programs [3,11]. Furthermore, results found different demographic and behavioural variables to be predictive of different patterns of adherence over the three year observation period. These findings support the hypothesis that different types of non-adherent behaviours are likely to respond to different types of interventions [9].

Identifying demographic sub groups less likely to respond to ongoing screening opportunities can assist with the design of targeted interventions to improve adherence [9]. Some demographic predictors of rescreening (for example, older age [17]) have already been identified. This study is 
Table 4 Significant social cognitive differences between consistent re-participation and each non-adherent category

\begin{tabular}{|c|c|c|c|c|c|c|c|}
\hline \multirow[t]{2}{*}{ Variable } & $\begin{array}{l}\text { Consistent } \\
\text { re-participation }(n=860)\end{array}$ & $\begin{array}{l}\text { Drop out } \\
(n=134)\end{array}$ & Intermittent re-participation $(n=68)$ & \multirow[t]{2}{*}{$\begin{array}{l}\text { Delayed entry } \\
\quad(n=166)\end{array}$} & \multirow[t]{2}{*}{$\begin{array}{c}\text { Consistent refusal } \\
\quad(n=312)\end{array}$} & \multirow[t]{2}{*}{$F(d f)$} & \multirow[t]{2}{*}{$p$} \\
\hline & Mean (SD) & & & & & & \\
\hline Barriers & $16.28(4.22)$ & $17.96(4.33)^{* *}$ & $16.51(3.65)$ & $16.57(4.34)$ & $18.04(4.80)^{* *}$ & $12.46(4,709.51)$ & $<.001$ \\
\hline Benefits & $16.14(1.96)$ & $15.74(1.99)$ & $15.96(1.75)$ & $15.90(1.93)$ & $15.07(2.24)^{* *}$ & $16.49(4,1535)$ & $<.001$ \\
\hline Self-efficacy & $23.73(4.69)$ & $22.36(4.29)^{*}$ & $23.63(4.22)$ & $23.35(4.61)$ & $21.57(5.01)^{* *}$ & $14.24(4,678.72)$ & $<.001$ \\
\hline Response efficacy & $11.06(1.45)$ & $11.26(1.13)$ & $10.79(1.88)$ & $10.96(1.61)$ & $10.46(1.73)^{* *}$ & $36.94(4)^{\mathrm{a}}$ & $<.001$ \\
\hline Social support & $22.96(3.81)$ & $22.91(3.61)$ & $22.88(3.26)$ & $22.47(3.52)$ & $21.80(4.38)^{* *}$ & $5.80(4,725.81)$ & $<.001$ \\
\hline Social influence & $13.76(2.60)$ & $13.52(2.61)$ & $13.13(2.65)$ & $13.38(2.43)$ & $12.75(2.78)^{* *}$ & $8.79(4,1535)$ & $<.001$ \\
\hline
\end{tabular}

Note. $\mathrm{F}=\mathrm{F}$ ratio; $\mathrm{df}=$ degrees of freedom, $\mathrm{SD}=$ standard deviation, $\mathrm{p}=$ probability. Data were measured on increasing, continuous scales.

${ }^{a}$ data were not normally distributed therefore the Kruskal-Wallis test was reported.

${ }^{*} p<.05 .{ }^{* *} p<.01$. 
Table 5 Demographic and background differences between consistent re-participation and categories of non-adherence

\begin{tabular}{|c|c|c|c|c|c|c|c|}
\hline Variable & $\begin{array}{c}\text { Consistent } \\
\text { re-participation }(n=860)\end{array}$ & $\begin{array}{l}\text { Drop out } \\
(n=134)\end{array}$ & $\begin{array}{c}\text { Intermittent } \\
\text { re-participation }(n=68)\end{array}$ & Delayed entry $(n=166)$ & Consistent refusal $(n=312)$ & $F(d f)$ & $p$ \\
\hline \multicolumn{8}{|l|}{ Mean(SD) } \\
\hline $\mathrm{Age}^{\mathrm{a}}$ & $61.18(6.33)$ & $58.86(6.55)^{* *}$ & $57.69(6.20)^{* *}$ & $57.86(5.57)^{* *}$ & $58.57(6.62)^{* *}$ & $19.92(4,599.32)$ & $<.001$ \\
\hline GP visits $^{a}$ & $3.98(1.16)$ & $4.04(1.13)$ & $3.47(1.31)^{* *}$ & $3.95(1.23)$ & $3.85(1.29)$ & $3.29(4,546.14)$ & .011 \\
\hline \multicolumn{6}{|c|}{ Number (\%) } & $x^{2}(\mathrm{df})$ & $p$ \\
\hline Private health insurance, None & $145(17.0)$ & $33(25.0)^{* *}$ & $17(25.0)$ & $31(18.7)$ & $75(24.1)$ & $26.80(12)$ & .008 \\
\hline Ancillary & $74(8.7)$ & $21(15.9)$ & $6(8.8)$ & $9(5.4)$ & $21(6.8)$ & & \\
\hline Hospital & $55(6.4)$ & $5(3.8)$ & $4(5.9)$ & $9(5.4)$ & $14(4.5)$ & & \\
\hline Both & $579(67.9)$ & $73(55.3)$ & $41(60.3)$ & $117(70.5)$ & $201(64.6)$ & & \\
\hline Gender (male) & $369(42.9)$ & $58(43.3)$ & $24(35.3)$ & $100(60.2)^{* *}$ & $159(51.0)$ & $23.48(4)$ & $<.001$ \\
\hline Married $(\text { yes })^{b}$ & $689(80.7)$ & $93(70.5) * *$ & $54(79.4)$ & $131(79.4)$ & $222(71.2)^{* *}$ & $16.46(4)$ & .002 \\
\hline Workforce (yes) ${ }^{b}$ & $383(45.4)$ & $78(60.0)^{* *}$ & $43(64.2)^{* *}$ & $109(66.5)^{* *}$ & $189(61.4)^{* *}$ & $45.88(4)$ & $<.001$ \\
\hline Disadvantage, 1 & $167(19.4)$ & $28(20.9)$ & $16(23.9)$ & $34(19.4)$ & $81(26.0)^{* *}$ & $36.73(16)$ & .002 \\
\hline 2 & $140(16.3)$ & $35(26.1)$ & $11(16.4)$ & $26(15.8)$ & $56(18.0)$ & & \\
\hline 3 & $152(17.7)$ & $20(14.9)$ & $16(23.9)$ & $20(12.1)$ & $39(12.5)$ & & \\
\hline 4 & $149(17.3)$ & $24(17.9)$ & $4(6.0)$ & $31(18.8)$ & $34(10.9)$ & & \\
\hline 5 (least) & $251(29.2)$ & $27(20.1)$ & $20(29.9)$ & $54(32.7)$ & $101(32.5)$ & & \\
\hline Knowledge (incorrect) ${ }^{c}$ & $124(14.5)$ & $23(17.2)$ & $13(19.4)$ & $23(13.9)$ & $72(23.1)^{* *}$ & $13.51(4)$ & .009 \\
\hline Known CRC (yes) ${ }^{b}$ & 622 (72.7) & $83(62.9)$ & $43(63.2)$ & 105 (63.6) & $191(62.0)^{* *}$ & 17.40 (4) & .002 \\
\hline Discussed FOBT (yes) ${ }^{b}$ & $542(63.0)$ & $65(48.9)^{* *}$ & $39(57.4)$ & $91(55.2)$ & $120(38.7)^{* *}$ & $57.59(4)$ & $<.001$ \\
\hline Known a screener (yes) ${ }^{b}$ & $469(54.7)$ & $54(40.6)^{* *}$ & $33(48.5)$ & $63(38.2)^{* *}$ & $93(30.1)^{* *}$ & $63.00(4)$ & $<.001$ \\
\hline Past other screening (yes) ${ }^{b}$ & $564(65.9)$ & $80(60.2)$ & $39(57.4)$ & $116(70.3)$ & $174(56.1)^{* *}$ & $14.42(4)$ & .006 \\
\hline SR past FOBT (yes) ${ }^{b}$ & $482(56.0)$ & $45(33.6)^{* *}$ & $32(47.1)$ & $83(50.0)$ & $78(25.0)^{* *}$ & 99.19 (4) & $<.001$ \\
\hline
\end{tabular}

Note. $S D=$ standard deviation; $F=F$ ratio; $x^{2}=$ chi square; $p=$ probability; $S E S=$ socioeconomic status determined by SEIFA index of disadvantage; knowledge = response to knowledge item regarding the importance of repeated screening; Known $C R C=$ known a person who has had $C R C$; Discussed FOBT $=$ ever discussed FOBT screening; Known a screener = known a person who has screened for CRC; Other screening = ever participated in other (not CRC) screening tests. SR past FOBT = self-reported past FOBT use . ${ }^{a}$ variables were measured on increasing, continuous scales; ${ }^{b}$ comparative category is 'no'; ${ }^{c}$ comparative category is 'correct' ${ }^{*} p<.05,{ }^{* *} p<.01$. 
Table 6 Multivariate predictors of non-adherence relative to consistent re-participation

\begin{tabular}{|c|c|c|c|c|c|c|c|c|c|c|c|c|c|}
\hline \multirow[t]{2}{*}{ Variable } & & \multicolumn{3}{|c|}{ Drop out $n=129^{a}$} & \multicolumn{3}{|c|}{$\begin{array}{c}\text { Intermittent } \\
\text { re-participation } n=67^{a}\end{array}$} & \multicolumn{3}{|c|}{$\begin{array}{l}\text { Delayed entry } \\
n=163^{\mathrm{a}}\end{array}$} & \multicolumn{3}{|c|}{$\begin{array}{l}\text { Consistent refusal } \\
n=300^{\mathrm{a}}\end{array}$} \\
\hline & & RR & $\mathrm{p}$ & $95 \% \mathrm{Cl}$ & RR & $p$ & $95 \% \mathrm{Cl}$ & RR & $p$ & $95 \% \mathrm{Cl}$ & $\mathbf{R R}$ & $p$ & $95 \% \mathrm{Cl}$ \\
\hline \multirow[t]{6}{*}{ Social cognitive } & Barriers & 1.05 & .032 & $(1.00-1.10)$ & & & & & & & 1.01 & .620 & $(0.98-1.03)$ \\
\hline & Benefits & & & & & & & & & & 0.97 & .231 & $(0.91-1.02)$ \\
\hline & Self-efficacy & 0.97 & .047 & $(0.94-1.00)$ & & & & & & & 0.97 & .004 & $(0.95-0.99)$ \\
\hline & Response efficacy & & & & & & & & & & 0.93 & .004 & $(0.88-0.98)$ \\
\hline & Social support & & & & & & & & & & 1.01 & .452 & $(0.99-1.04)$ \\
\hline & Social influence & & & & & & & & & & 0.97 & .281 & $(0.93-1.02)$ \\
\hline \multirow[t]{7}{*}{ Background } & Known $C R C$ (yes) $^{b}$ & & & & & & & & & & 0.88 & .173 & $(0.73-1.06)$ \\
\hline & Discussed FOBT (yes) ${ }^{b}$ & 1.02 & .917 & $(0.71-1.47)$ & & & & & & & 0.97 & .806 & $(0.77-1.23)$ \\
\hline & Known a screener (yes) ${ }^{b}$ & 0.86 & .390 & $(0.60-1.22)$ & & & & 0.72 & .029 & $(0.53-0.97)$ & 0.73 & .010 & $(0.58-0.93)$ \\
\hline & GP visits & & & & 0.80 & .015 & $(0.67-0.96)$ & & & & & & \\
\hline & Knowledge (incorrect) ${ }^{c}$ & & & & & & & & & & 1.07 & .573 & $(0.85-1.33)$ \\
\hline & Other screening (yes) ${ }^{b}$ & & & & & & & & & & 0.88 & .168 & $(0.73-1.06)$ \\
\hline & SR past FOBT (yes) $)^{b}$ & 0.66 & .042 & $0.44-0.98$ & & & & & & & 0.59 & $<.001$ & $(0.45-0.77)$ \\
\hline \multirow[t]{11}{*}{ Demographic } & Age & 0.98 & .157 & $(0.94-1.01)$ & 0.93 & .007 & $(0.88-0.98)$ & 0.94 & $<.001$ & $(0.91-0.97)$ & 0.98 & .011 & $(0.96-0.99)$ \\
\hline & Workforce (yes) ${ }^{b}$ & 1.38 & .116 & $(0.93-2.05)$ & 1.05 & .869 & $(0.60-1.82)$ & 1.21 & .302 & $(0.84-1.75)$ & 1.25 & .064 & $(0.99-1.57)$ \\
\hline & Married (yes) ${ }^{b}$ & 0.77 & .133 & $(0.54-1.09)$ & & & & & & & 0.82 & .068 & $(0.67-1.02)$ \\
\hline & Private insurance (none) ${ }^{d}$ & 1.43 & .076 & $(0.96-2.13)$ & & & & & & & & & \\
\hline & $\begin{array}{l}\text { Private insurance } \\
\text { (ancillary only) }^{d}\end{array}$ & 1.57 & .044 & $(1.01-2.43)$ & & & & & & & & & \\
\hline & $\begin{array}{l}\text { Private insurance } \\
\text { (hospital only) }^{d}\end{array}$ & 0.75 & .501 & $(0.33-1.73)$ & & & & & & & & & \\
\hline & Gender (male) & & & & & & & 1.77 & $<.001$ & $(1.32-2.38)$ & & & \\
\hline & Disadvantage (1) & & & & & & & & & & 0.99 & .926 & $(0.78-1.25)$ \\
\hline & Disadvantage (2) & & & & & & & & & & 0.87 & .312 & $(0.66-1.14)$ \\
\hline & Disadvantage (3) & & & & & & & & & & 0.71 & .031 & $(0.53-0.97)$ \\
\hline & Disadvantage $(4)^{f}$ & & & & & & & & & & 0.76 & .098 & $(0.55-1.05)$ \\
\hline
\end{tabular}

Note. $\mathrm{RR}=$ risk ratio; $\mathrm{p}=$ probability; significance level is $\mathrm{p}<.05$, significant values in bold; $95 \% \mathrm{Cl}=$ confidence interval. Social cognitive variables, $\mathrm{GP}$ visits and age were measured on increasing, continuous scales.

knowledge = response to knowledge item regarding the importance of repeated screening; Known CRC = known a person who has had CRC; DisCussed FOBT = ever discussed FOBT screening; Known a screener = known a person who has screened for CRC; Other screening = ever participated in other (not CRC) screening tests; SR past $F O B T=$ self-reported past FOBT use ${ }^{a}$ Cases with missing data were removed list wise, group totals reported in the table report the number of participants included in

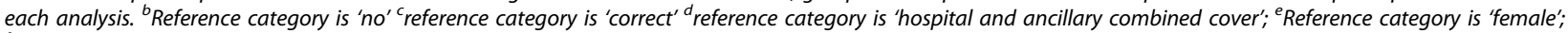
${ }^{f}$ Reference category is the fifth quintile of disadvantage (least disadvantage).

the first to examine predictors of adherence after more than two screening rounds, and included a broad range of demographic variables, which led to some new findings. For example, results showed that men were more likely to delay participation in the screening program. Prior research has consistently reported lower levels of initial FOBT participation amongst men [32-34]. However these findings suggest that men may simply take longer to respond to invitations to screen, and may benefit from different recruitment strategies than women to encourage first time compliance. Similarly, having private health insurance for ancillary services only was predictive of screening drop out but not associated with other behaviours including consistent nonparticipation. Results may reflect concerns about ongoing costs resulting from follow up testing in initial screening rounds [35]. Screening programs may want to consider finding means of providing free follow up examinations to encourage rescreening.

Consistent with our previous research on rescreening intention [15], satisfaction with past FOBT screening was a strong behavioural predictor of adherence to the study FIT offers. Satisfaction was one of the few variables to predict multiple screening behaviours with less satisfaction with past screening predicting likelihood of drop out, consistent refusal and delayed entry behaviour by $40 \%, 26 \%$ and $22 \%$ respectively. The mammography screening literature has consistently shown less satisfaction with initial screening to be predictive of non- 
Table 7 Multivariate predictors of non-adherence relative to consistent re-participation including a measure of prior satisfaction with FOBT

\begin{tabular}{|c|c|c|c|c|c|c|c|c|c|c|c|c|c|}
\hline \multirow[t]{2}{*}{ Variable } & & \multicolumn{3}{|c|}{ Drop out $n=40^{a}$} & \multicolumn{3}{|c|}{ Intermittent re-participation $n=31^{a}$} & \multicolumn{3}{|c|}{ Delayed entry $n=81^{a}$} & \multicolumn{3}{|c|}{ Consistent refusal $n=76^{a}$} \\
\hline & & RR & $p$ & $95 \% \mathrm{Cl}$ & RR & $p$ & $95 \% \mathrm{Cl}$ & RR & $p$ & $95 \% \mathrm{Cl}$ & RR & $p$ & $95 \% \mathrm{Cl}$ \\
\hline \multirow{7}{*}{$\begin{array}{l}\text { Behavioural (social cognitive } \\
\text { and satisfaction) }\end{array}$} & Barriers & 1.07 & .112 & $(0.98-1.17)$ & & & & & & & 1.00 & .873 & $(0.93-1.06)$ \\
\hline & Benefits & & & & & & & & & & 1.01 & .936 & $(0.89-1.14)$ \\
\hline & Self-efficacy & 1.00 & .965 & $(0.94-1.17)$ & & & & & & & 1.00 & .847 & $(0.96-1.05)$ \\
\hline & Response efficacy & & & & & & & & & & 0.94 & .333 & $(0.82-1.07)$ \\
\hline & Social support & & & & & & & & & & 1.02 & .455 & $(0.97-1.08)$ \\
\hline & Social influence & & & & & & & & & & 0.94 & .186 & $(0.86-1.03)$ \\
\hline & Satisfaction & 0.60 & $<.001$ & $(0.46-0.78)$ & 0.99 & .960 & $(0.66-1.48)$ & 0.78 & .008 & $(0.65-0.94)$ & 0.74 & .005 & $(0.60-0.92)$ \\
\hline \multirow[t]{6}{*}{ Background } & Known CRC (yes) $)^{b}$ & & & & & & & & & & 0.80 & .348 & $(0.51-1.27)$ \\
\hline & Discussed FOBT (yes) ${ }^{b}$ & 0.84 & .642 & $(0.40-1.75)$ & & & & & & & 0.82 & .465 & $(0.50-1.37)$ \\
\hline & Known screener (yes) ${ }^{b}$ & 1.20 & .582 & $(0.62-2.31)$ & & & & 0.76 & .183 & $(0.51-1.14)$ & 0.74 & .153 & $(0.49-1.11)$ \\
\hline & GP visits & & & & 0.64 & $<.001$ & $(0.51-0.82)$ & & & & & & \\
\hline & knowledge (incorrect) ${ }^{c}$ & & & & & & & & & & 1.27 & .458 & $(0.67-2.40)$ \\
\hline & Other screening (yes) ${ }^{b}$ & & & & & & & & & & 0.97 & .891 & $(0.63-1.50)$ \\
\hline \multirow[t]{8}{*}{ Demographic } & Age & 0.99 & .654 & $(0.93-1.05)$ & 0.96 & .218 & $(0.89-1.03)$ & 0.93 & $<.001$ & $(0.89-0.97)$ & 0.97 & .209 & $(0.93-1.02)$ \\
\hline & Workforce (yes) & 1.92 & .067 & $(0.95-3.84)$ & 1.49 & .256 & $(0.75-3.00)$ & 1.41 & .198 & $(0.84-2.39)$ & 1.73 & .054 & $(0.99-3.03)$ \\
\hline & Married (yes) $)^{b}$ & 0.95 & .896 & $(0.45-1.95)$ & & & & & & & 0.98 & .918 & $(0.61-1.57)$ \\
\hline & Gender $(\text { male })^{d}$ & & & & & & & 2.00 & .002 & $(1.30-3.10)$ & & & \\
\hline & Disadvantage (1) & & & & & & & & & & 0.49 & .050 & $(0.24-1.00)$ \\
\hline & Disadvantage (2) & & & & & & & & & & 0.66 & .155 & $(0.37-1.17)$ \\
\hline & Disadvantage (3) & & & & & & & & & & 0.41 & .023 & $(0.19-0.88)$ \\
\hline & Disadvantage (4) ${ }^{e}$ & & & & & & & & & & 0.48 & .032 & $(0.25-0.94)$ \\
\hline
\end{tabular}

Note. $\mathrm{RR}=$ risk ratio; $\mathrm{p}=$ probability, $95 \% \mathrm{Cl}=$ confidence interval.Social cognitive variables, satisfaction, GP visits and age were measured on increasing, continuous scales. Health insurance was not included as a predictor in secondary analyses as cell sizes were $<5$ for drop out participants with only ancillary and only hospital cover.

knowledge= response to knowledge item regarding the importance of repeated screening; Known CRC= known a person who has had CRC; Discussed FOBT= ever discussed FOBT screening; Known a screener=

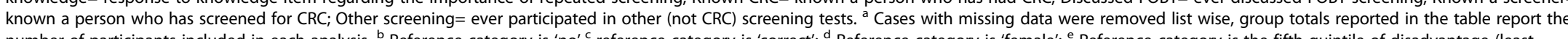

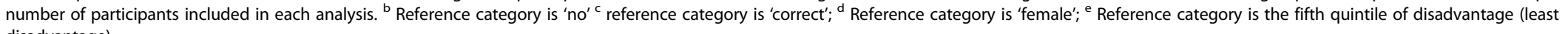
disadvantage). 
adherence to a subsequent offer [36,37]. Results of the present study indicate that satisfaction can also have an ongoing effect on adherence leading to consistent refusal of multiple screening offers as well as irregular participatory patterns. The importance of ensuring initial and continued satisfaction with screening cannot be underestimated. Future rescreening research should consider exploring which aspects of screening, for example, the type of FOB test utilised [38], the service provided as part of the screening experience [37] or the receipt of abnormal test results [16] may contribute to perceived satisfaction and how these factors may be improved to encourage rescreening.

A review of the screening literature where faecal occult blood tests have been used indicates that social cognitive variables can predict initial screening uptake [12] and rescreening intention [15]. In the present study, greater perceived barriers and less self-efficacy predicted drop out behaviour whilst less self-efficacy and less confidence in the efficacy of the test (response efficacy) predicted consistent non-participation. Social cognitive variables did not predict either delayed entry or inconsistent reparticipation. Results indicate that interventions targeting relevant beliefs, for example those that aim to reduce perceived barriers to screening, emphasise the utility of FOBT for early detection (e.g., improve perceived effectiveness and utility of the screening test), and highlight ease and simplicity of testing (e.g., improve confidence in personal ability to complete the test), may improve rescreening adherence for subgroups of the population.

The relationship between greater perceived barriers, lower self-efficacy and non-adherence to initial screening has been well established $[12,13]$. The finding that consistent refusal of screening in this study was associated with lower response efficacy for FOBT screening is an interesting contribution. Whilst several qualitative studies have highlighted participant concerns about the efficacy of home stool tests [35,39] few quantitative investigations have established a relationship between these beliefs and initial participation. The results of the present study may indicate that the behaviour of refusing a single screening offer is different from the behaviour of refusing multiple screening offers. Consistent refusal might instead reflect an informed decision (the decision to refuse screening is based on adequate knowledge of the screening test, its purpose and limitations [40]) to not participate in FOB-based CRC screening. Further research is required to establish whether lower response efficacy for FOBT in this study was a result of inadequate knowledge of FOBT or reflects a preference for alternate forms of screening such as colonoscopy.

Whilst this study identified several social cognitive predictors of patterns of adherence, the risk ratios associated with these predictors were smaller than those of similar studies in the initial screening literature $[25,41]$. There are several possible explanations for this finding.

Firstly, this study utilised a prospective design where beliefs about FOBT screening were obtained before the study outcomes (participation in three rounds of screening) were measured. Results presented here therefore cannot account for possible changes in these beliefs that may have occurred over the three year screening period [42]. Secondly, whilst the study utilised existing social cognitive scales where possible, some variables (for example, severity) were measured using only two items, whilst satisfaction was measured with only one item. It may be necessary to include more extensive measures in the future in order to increase the reliability of the results, particularly in relation to satisfaction. Results may also indicate that additional psychosocial variables are required to explain adherence behaviour. Future research should consider exploring the use of other behavioural variables, for example those associated with behaviour maintenance (for example, planning processes and maintenance self-efficacy [43]), to better explain variations in rescreening adherence.

Finally, the small sample sizes of some adherence categories (for example the drop out and intermittent reparticipation categories), particularly in the secondary analyses, should also be taken into consideration. Ideally, for multivariate analyses, the number of parameters included in each model should be $n / 10$ - 1 where $n$ is the sample size of the smallest comparison group [44]. Whilst these requirements were met in the primary analyses, the group sizes were too small to meet these requirements amongst the satisfaction subgroup analyses. It is possible therefore that the contribution of the social cognitive variables were small or nonexistent as a result of the small sample size rather than a lack of association. Repeating the analyses with a larger sample, or collapsing some of the adherence categories, may be required to establish the contribution of social cognitive variables to adherence behaviour particularly when satisfaction with prior screening is taken into consideration.

This study is amongst the first to document patterns of ongoing adherence to FOBT screening $[9,11]$. In this study, outcomes were based on both observed (per protocol) and observed plus self-reported (per and ex protocol) adherence to annual FOB-based screening. The inclusion of self-report data ensured that participants were not misclassified as being non-adherent when screening had occurred independent of the study [45]. This is particularly important in the current Australian context where a national bowel cancer screening program offers free screening to select age groups within the target population [3,5] and people can also access tests from doctors and pharmacies. Self-report data however is limited by inaccurate recall [46] and the potential for participants to exaggerate compliance to conform 
with study or personal expectations [47]. Whilst efforts were made to simplify self-report by restricting recall to a single recent screening experience [48,49], results should be interpreted in light of these potential limitations. In addition, this study measured adherence to an annual program of FIT screening. Australian screening recommendations allow for either an annual or beiannial screening interval [2] and it is therefore possible that some participants participated irregularly as a result of these recommendations.

This study is the first to identify differences in behavioural and demographic characteristics of non-adherence beyond two screening rounds. Whilst observed differences between the adherence categories for demographic, background and social cognitive variables support the use of a descriptive framework for understanding rescreening adherence there are limitations to this approach.

Screening participation is an ongoing behaviour; the analyses presented here describe participants based on observed behaviour only over three consecutive screening rounds, and labels assigned to participants' behaviours will change from one round to the next; category membership is not fixed. The findings presented here suggest characteristics that may be targeted at a broad population level to improve rates of participation; but they may not be useful for determining how an individual may behave in the future.

In addition, predefined behavioural definitions were used to guide the categorisation of invitees and some definitions collapsed multiple patterns of behaviour. This approach was beneficial as it allowed for a detailed comparison of several different types of adherence behaviour without focusing on all eight of the observed patterns. This is particularly relevant for studies focusing on greater numbers of screening rounds, where possible patterns of behaviour will continue to increase. This approach does however overlook the potential for differences within the categories, for example, potential differences between sustained and sporadic participation [9]. Future research may want to consider exploring alternate rules for categorisation in order to determine the most effective approach for describing, and improving, rescreening adherence.

\section{Conclusions}

This study identified several demographic, background and behavioural variables predictive of non-adherence to three annual offers of FIT screening for CRC. Different combinations of demographic and behavioural variables predicted different patterns of rescreening adherence. Less satisfactory experiences with screening before study involvement was a major determinant of non-adherence to the screening offered in the study.

\section{Endnote}

a'Ancillary only' is a private health insurance policy available in Australia that provides benefits for ancillary treatments (e.g., dental, physiotherapy) but does not provide benefits for hospital visits.

\section{Abbreviations}

ANOVA: Analysis of variance; BHS: Bowel health service; CRC: Colorectal cancer; FIT: Faecal immunochemical test; FOBT: Faecal occult blood test: FS: Flexible sigmoidoscopy; GEE: Generalised estimating equations; GP: General practitioner; RR: Risk ratios

\section{Competing interests}

All authors declare that they have no competing interests.

\section{Authors' contributions}

AD contributed to the design of the study and the survey materials, was involved in participant recruitment and data collection, conducted the analyses and drafted the manuscript. DT and CW were responsible for the conception and design of the study, contributed to the development of survey materials, assisted with interpretation of analyses and made substantial contributions to the drafting of the manuscript. JO was involved in participant recruitment, data collection, initial analyses and contributed to the drafting of the manuscript. SC, IF and GP were responsible for the conception and design of the study, contributed to the development of study materials and to the drafting of the manuscript. All authors read and approved the final manuscript.

\section{Acknowledgements}

This research is funded by National Health and Medical Research Council, project grant number 480428 .

\section{Author details}

'School of Psychology, The University of Adelaide, Adelaide 5005, South Australia, Australia. ${ }^{2}$ Cancer Council South Australia, Eastwood 5063, South Australia, Australia. ${ }^{3}$ Flinders Centre for Innovation in Cancer, Flinders University, Bedford Park 5042, South Australia, Australia. ${ }^{4}$ Bowel Health Service, Repatriation General Hospital, Daw Park 5041, South Australia, Australia. ${ }^{5}$ Preventative Health Flagship, Commonwealth Scientific and Industrial Research Organisation (CSIRO), Adelaide 5000, South Australia, Australia

Received: 12 September 2013 Accepted: 3 March 2014 Published: 7 March 2014

\section{References}

1. Hewitson P, Glasziou P, Watson E, Towler B, Irwig L: Cochrane systematic review of colorectal cancer screening using the fecal occult blood test (Hemoccult): an update. Am J Gastroenterol 2008, 103:1541-1549.

2. Australian Cancer Network Colorectal Cancer Guidelines Revision Committee: Guidelines for the Prevention, early Detection and Management of Colorectal Cancer. Sydney: The Cancer Council Australia and Australian Cancer Network; 2005.

3. Young GP: Population-based screening for colorectal cancer: Australian research and implementation. J Gastroenterol Hepatol 2009, 24:S33-S42.

4. Benson VS, Patnick J, Davies AK, Nadel MR, Smith RA, Atkin WS: Colorectal cancer screening: a comparison of 35 initiatives in 17 countries. Int J Cancer 2008, 122:1357-1367.

5. Australian Institute of Health and Welfare: National Bowel Cancer Screening Program monitoring report: July 2011-June 2012. Cancer series no. 75 Cat. no. CAN 71. Canberra: AlHW; 2013.

6. Jorgensen $\mathrm{OD}$, Kronborg $\mathrm{O}$, Fenger $\mathrm{C}$ : A randomised study of screening for colorectal cancer using faecal occult blood testing: results after 13 years and seven biennial screening rounds. Gut 2002, 50:29-32.

7. Gellad ZF, Stechuchak KM, Fisher DA, Olsen MK, McDuffie JR, Ostbye T, Yancy WS: Longitudinal adherence to fecal occult blood testing impacts colorectal cancer screening quality. Am J Gastroenterol 2011, 106:1125-1134.

8. Cooper GS, Doug Kou T: Underuse of colorectal cancer screening in a cohort of medicare beneficiaries. Cancer 2008, 112:293-299. 
9. Cole SR, Gregory T, Whibley A, Ward P, Turnbull D, Wilson C, Flight I, Esterman A, Young GP: Predictors of re-participation in faecal occult blood test- based screening for colorectal cancer. Asian Pac J Cancer Prev 2012, 13:5989-5994.

10. Denters MJ, Deutekom M, Bossuyt PM, van Rijn AF, Fockens P, Dekker E: Involvement of previous non-participants cannot fully compensate for lower participation in a second round of FIT-screening. Can Epidemiol 2013, 37:330-335.

11. Steele RJC, McClements PL, Libby G, Carey FA, Fraser CG: Patterns of uptake in a biennial faecal occult blood test (FOBT) screening programme for colorectal cancer. Color Dis 2014, 16:28-32.

12. Kiviniemi MT, Bennett A, Zaiter M, Marshall JR: Individual-level factors in colorectal cancer screening: a review of the literature on the relation of individual-level health behavior constructs and screening behavior. Psycho-Oncology 2011, 20:1023-1033.

13. Beydoun HA, Beydoun MA: Predictors of colorectal cancer screening behaviors among average-risk older adults in the United States. Cancer Causes Control 2008, 19:339-359.

14. Holden DJ, Jonas DE, Porterfield DS, Reuland D, Harris R: Systematic review: enhancing the use and quality of colorectal cancer screening. Ann Intern Med 2010, 152:668-676.

15. Duncan A, Turnbull D, Gregory T, Cole SR, Young G, Flight I, Wilson C: Using the Transtheoretical Model of Behaviour Change to describe readiness to rescreen for colorectal cancer with faecal occult blood testing. Health Promot $\rfloor$ Aust 2012, 23:122-128.

16. Garcia M, Maria Borràs J, Binefa G, Milà N, Alfons Espinàs J, Moreno V: Repeated screening for colorectal cancer with fecal occult blood test in Catalonia, Spain. Eur J Cancer Prev 2012, 21:42-45.

17. Fenton JJ, Elmore JG, Buist DS, Reid RJ, Tancredi DJ, Baldwin L-M: Longitudinal adherence with fecal occult blood test screening in community practice. Ann Fam Med 2010, 8:397-401.

18. Janda M, Hughes KL, Auster JF, Leggett BA, Newman BM: Repeat participation in colorectal cancer screening utilizing fecal occult blood testing: a community-based project in a rural setting. J Gastroenterol Hepatol 2010, 25:1661-1667.

19. Liss DT, Petit-Homme A, Feinglass J, Buchanan DR, Baker DW: Adherence to repeat fecal occult blood testing in an urban Community Health Center Network. J Community Health 2013, 38:829-833.

20. Drossaert CHC, Boer $\mathrm{H}$, Seydel ER: Prospective study on the determinants of repeat attendance and attendance patterns in breast cancer screening using the theory of planned behaviour. Psychol Health 2003, 18:551-565.

21. Champion V, Maraj M, Hui S, Perkins AJ, Tierney W, Menon U, Skinner CS: Comparison of tailored interventions to increase mammography screening in nonadherent older women. Prev Med 2003, 36:150-158.

22. Sohl SJ, Moyer A: Tailored interventions to promote mammography screening: a meta-analytic review. Prev Med 2007, 45:252-261.

23. Rozen P, Young G, Levin B, Spann S: Colorectal Cancer in Clinical Practice; Prevention, early Detection and Management. 2nd edition. London and New York: Taylor \& Francis; 2006

24. Pink B: Census of Population and Housing: Socio-Economic Indexes for Area's (SEIFA)Technical Paper (2039.0.55.001). Canberra: Australian Bureau of Statistics; 2004.

25. Gregory T, Wilson C, Duncan A, Turnbull D, Cole SR, Young GP: Demographic, social cognitive and social ecological predictors of intention and participation in screening for colorectal cancer. BMC Public Health 2011, 11:38.

26. Luszczynska A, Schwarzer R: Planning and self-efficacy in the adoption and maintenance of breast self-examination: a longitudinal study on self-regulatory cognitions. Psychol Health 2003, 18:93-108.

27. Wallston KA, Strudler Wallston B, De Vellis R: Development of the Multidimensional Health Locus of Control (MHLC) Scales. Health Educ Behav 1978, 6:160-170

28. Lau RR, Hartman KA: Health as a value: methodological and theoretical considerations. Health Psychol 1986, 5

29. Boer H, Seydel ER: Protection Motivation Theory. In Predicting Health Behaviour. Edited by Conner M, Norman P. Buckingham: Open University Press; 1996:95-120

30. Tiro J, Vernon SW, Hyslop T, Myers R: Factorial validity and invariance of a survey measuring psychosocial correlates of colorectal cancer screening among African Americans and Caucasians. Canc Epidemiol Biomarkers Prev 2005, 14:2855-2861.
31. Neideen T, Brasel K: Understanding statistical tests. J Surg Educ 2007, 64:93-96.

32. Le Retraite L, Eisinger F, Loundou A, Rinaldi Y, Seitz JF, Auquier P: Sociogeographical factors associated with participation in colorectal cancer screening. Gastroenterol Clin Biol 2010, 34:534-540.

33. Pornet C, Dejardin O, Morlais F, Bouvier V, Launoy G: Socioeconomic determinants for compliance to colorectal cancer screening. A multilevel analysis. J Epidemiol Community Health 2010, 64:318-324.

34. Ward PR, Javanparast S, Matt MA, Martini A, Tsourtos G, Cole S, Gill T, Aylward P, Baratiny G, Jiwa M, Misan G, Wilson C, Young G: Equity of colorectal cancer screening: cross-sectional analysis of national bowel cancer screening program data for South Australia. Aust N Z J Public Health 2011, 35:61-65.

35. Beeker C, Kraft J, Southwell B, Jorgensen C: Colorectal cancer screening in older men and women: qualitative research findings and implications for interventions. J Community Health 2000, 25:263-278.

36. Peipins L, Shapiro J, Bobo J, Berkowitz Z: Impact of women's experiences during mammography on adherence to rescreening (United States). Cancer Causes Control 2006, 17:439-447.

37. Tang TS, Patterson SK, Roubidoux MA, Linping D: Women's mammography experience and its impact on screening adherence. Psycho-Oncology 2009, 18:727-734.

38. Cole SR, Young GP, Esterman A, Cadd B, Morcom J: A randomised trial of the impact of new faecal haemoglobin test technologies on population participation in screening for colorectal cancer. J Med Screen 2003, 10:1-6.

39. Clavarino A, Del Mar C, Aitken JF, Janda M, Tong S, Leggett B, Hughes K, Stanton WR, Newman B: The view from two sides: a qualitative study of community and medical perspectives on screening for colorectal cancer using FOBT. Prev Med 2004, 39:482-490.

40. Smith S, Trevena L, Simpson J, Barratt A, Nutbeam D, McCaffery K: A decision aid to support informed choices about bowel cancer screenign among adults with low education: randomised controlled trial. Br Med J 2010, 341:971-981.

41. Cole SR, Zajac I, Gregory T, Mehaffey S, Roosa N, Turnbull D, Esterman A, Young G: Psychosocial variables associated with colorectal cancer screening in South Australia. Int I Behav Med 2011, 18:302-309.

42. Cooke R, French DP: How well do the theory of reasoned action and theory of planned behaviour predict intentions and attendance at screening programmes? A meta-analysis. Psychol Health 2008, 23:745-765.

43. Schwarzer R: Modeling health behaviour change: how to predict and modify the adoption and maintenance of health behaviours. Appl Psychol 2008, 57:1-29.

44. Hosmer DW, Lemeshow S: Applied Logistic Regressions. 2nd edition. New York: John Wiley and Sons; 2000.

45. Zajac I, Flight I, Turnbull D, Young G, Cole S, Wilson C: Self-reported bowel screenign rates in older Australian and the implications for public health screening programs. Australas Med J 2013, 6:411-417.

46. Vernon SW, Briss PA, Tiro JA, Warnecke RB: Some methodologic lessons learned from cancer screening research. Cancer 2004, 101:1131-1145.

47. Festinger $L$, Carlsmith JM: Cognitive consequences of forced compliance. J Abnorm Soc Psych 1959, 58:203-210.

48. Rauscher GH, O'Malley MS, Earp JAL: How consistently do women report lifetime mammograms at successive interviews? Am J Prev Med 2002, 22:8-14.

49. Vernon SW, Meissner H, Klabunde C, Rimer BK, Ahnen DJ, Bastani R, Mandelson MT, Nadel MR, Sheinfeld-Gorin S, Zapka J: Measures for ascertaining use of colorectal cancer screening in behavioral, health services, and epidemiologic research. Canc Epidemiol Biomarkers Prev 2004, 13:898-905

doi:10.1186/1471-2458-14-238

Cite this article as: Duncan et al:: Behavioural and demographic predictors of adherence to three consecutive faecal occult blood test screening opportunities: a population study. BMC Public Health 2014 14:238. 